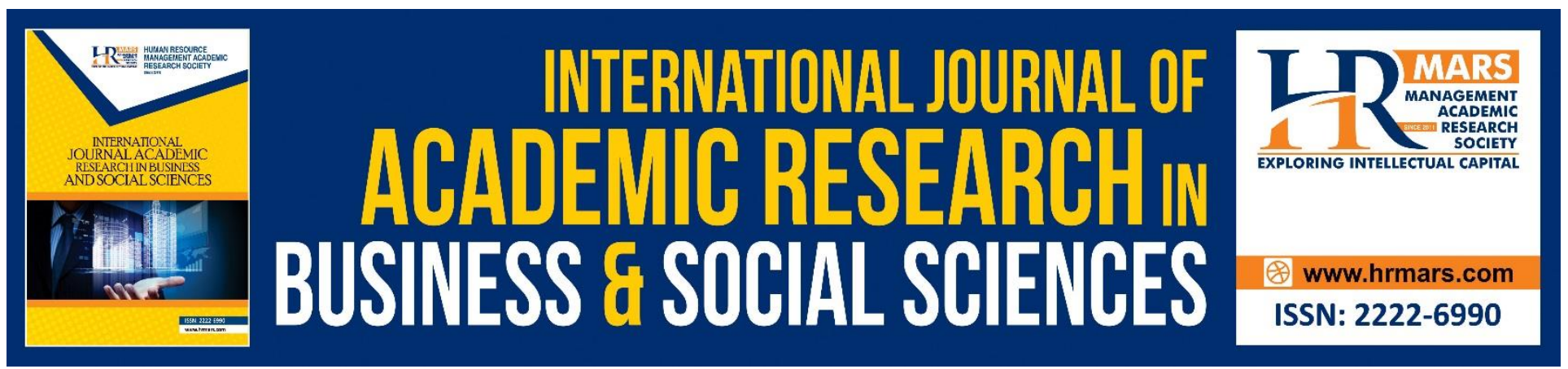

\title{
Teachers' Readiness to Accommodate Autistic Children in the Classrooms at International Schools
}

\author{
Noshini Uithayakumar, Norfishah Mat Rabi
}

To Link this Article: http://dx.doi.org/10.6007/IJARBSS/v10-i7/7613

DOI:10.6007/IJARBSS/v10-i7/7613

Received: 23 April 2020, Revised: 24 May 2020, Accepted: 16 June 2020

Published Online: 01 July 2020

In-Text Citation: (Uithayakumar \& Rabi, 2020)

To Cite this Article: Uithayakumar, N., \& Rabi, N. M. (2020). Teachers' Readiness to Accommodate Autistic Children in the Classrooms at International Schools. International Journal of Academic Research in Business and Social Sciences, 10(7), 831-837.

Copyright: (C) 2020 The Author(s)

Published by Human Resource Management Academic Research Society (www.hrmars.com)

This article is published under the Creative Commons Attribution (CC BY 4.0) license. Anyone may reproduce, distribute, translate and create derivative works of this article (for both commercial and non-commercial purposes), subject to full attribution to the original publication and authors. The full terms of this license may be seen

at: http://creativecommons.org/licences/by/4.0/legalcode

Vol. 10, No. 7, 2020, Pg. 831 - 837

Full Terms \& Conditions of access and use can be found at http://hrmars.com/index.php/pages/detail/publication-ethics 


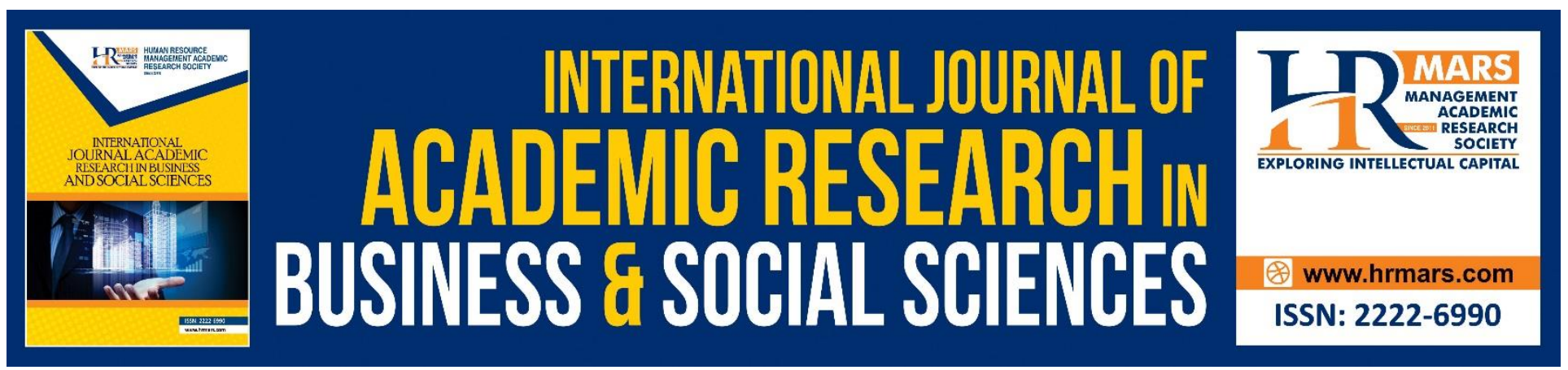

\title{
Teachers' Readiness to Accommodate Autistic Children in the Classrooms at International Schools
}

\author{
Noshini Uithayakumar, Norfishah Mat Rabi \\ Faculty of Human Development, Universiti Pendidikan Sultan Idris, Malaysia.
}

\begin{abstract}
This study's aim is to understand teacher's readiness to accommodate autistic children in classrooms at international schools. This study has recounted a problem where majority of teachers in international school are not ready to accommodate autistic children in their classroom, where teachers with no qualification or experience to teach these autistic children. This research has focused on interviews and observations on three teachers who are currently teaching at international schools. The transcript was codded according to themes and subthemes. The Creswell method was to analyze the data of the interview. The findings show that, most teachers at international are not competent to accommodate the autistic children in their respective classrooms based on their experience and qualification. As a conclusion, before an autistic child is put into an international school, the school must only accept the child if they are well equipped with facilities and well trained teachers to educated these special children. The study implicates that, all international schools who accepts autistic children into the school have to provide necessary training for the teaching staff on how to handle and accommodate these autistic children in the classroom.
\end{abstract}

Keywords: Autistic Children, Qualifications, Teachers, International Schools, Readiness.

\section{Introduction}

This study's aim is to understand teacher's readiness to accommodate autistic children in classrooms at international schools. Beginning school is viewed as a basic event in a child's advancement and effective changes to class have been placed as key markers for future scholastic accomplishment. For this study, teachers from an International school who teaches autism children are interviewed. Autism and its associated behaviors have been estimated to occur in as many as 1 in 68 new-borns. Parents usually see the symptoms in the children between the ages of two and six. Teacher's qualification in international school are different compared to government and other private schools. Emphasizing the qualification of special needs education at international schools are not looked into. It's just an additional qualification but not a requirement. Teachers who has no training or certificate on how to educate these autistic children will face difficulties at school. there are certain autism children are studying at international schools around Malaysia. These children are place together with normal students in a classroom. There's always differentiation in learning among different type of children in a classroom. The teachers need to be competent enough to accommodate autistic 
children into a normal classroom as the other children. Certain teachers are well trained and certain teachers are not exposed in handling these children in certain schools. In order for teachers to accommodate the individual needs of an autistic child they need to constantly improve the skills and knowledge that will assist them in the development of such children's strengths and competencies as well as in dealing with the behavioral, sensory, emotional, communicative and social balances (Denysschen, 2008). Across all types of educational settings, teachers and parents interviewed noted that many teachers they had encountered lacked sufficient training and support to cope with the rising demands of special needs education. In almost every setting, parents described long waiting lists and difficulty in securing a place for their child (Lim, 2015). Children that are mainstreamed in a classroom still struggle with these issues which can make their experience unsuccessful and cause them to feel alone. In order for these children to be successful in the classroom, teachers need to understand the children's' strengths and know how to best help them participate in a meaningful way (Hart \& Whalon, 2011). Autistic children must be able to use the general necessary support in the classroom that they are placed with the other mainstream children and are the teachers have enough exposure accommodating the autism children in a normal classroom. Teachers need support and strategies to work with children on the spectrum in their classrooms. With direct support from trained personnel, teachers can help their students achieve success (Davis \& Meredith, 2013).

\section{Literature Review}

Autism could not be what we think it is. Autism is something we'll probably never all agree about. Autism is not just found in children. Given the high incidence of autism spectrum disorder (ASD), at close to $1 \%$ worldwide (Lai et al., 2014). ASD is a neurodevelopmental disorder which is characterized by pervasive difficulties in interaction and communication that are accompanied by unusually restricted, repetitive behavior and interests since early childhood (Lai et al., 2015). Autism, or autism spectrum disorder, refers to a range of conditions characterized by challenges with social skills, repetitive behaviours, speech and nonverbal communication, as well as by unique strengths and differences. We now know that there is not one autism but many types, caused by different combinations of genetic and environmental influences (Autism Speaks Inc. Autism Speaks and Autism Speaks Its Time to Listen \& Design, 2018)

Not all experienced teachers have had the opportunity to acquire the necessary knowledge and skills. This includes being able to identify students' individual learning needs; planning and implementing evidence informed learning programs to meet these needs; and recording and monitoring progress and outcomes (NCES, 2016). Special education teachers alone cannot meet the diverse needs of these students, and consultation with single building or district "experts" is no longer a viable alternative for this burgeoning population. Flexible, ongoing training and support are required in order for educators to adequately and appropriately serve students with ASDs in a variety of settings (Sandford \& Cheryl, 2009). Research reveals that even when teachers feel collaborative practices are institutionalized in schools, the use of such practices is not always implemented (Damore \& Murray, 2009). Teachers confront difficulties in their first years of the profession and they cannot teach effectively. Special education teacher training programs must be improved by carefully evaluating the needs of the pre- and in-service teachers. Undergraduate programs of special education teacher training must contain more practice (Ergül, Baydik \& Demir, 2013).

A good practice in autism education is relation between 'quality first' classroom and school practice, specialist approaches that are relevant for working with many pupils with SEN and their 
families; and highly specialist approaches that might be required specifically for pupils with autism. It is important to emphasise at the outset that all 'good practice' in autism education will rest on the foundation of 'quality first' teaching practice (CRAE, 2011). Music is effective in increasing mean percentages of on-task behaviour for young children with ASD, when compared with spoken instructions and/or instructor demonstrations alone. Students exhibited higher mean percentages of on-task behavior when presented with the condition that included music with lyrics plus instruction (Dieringer, Porretta \& Sainato, 2017). Regular, accurate and comprehensive assessments of students with ASD form the foundation for effective programs, services and professional development. It is important to separate the concepts of curriculum and instructional approach (Ministers' Autism Spectrum Disorders, 2007). Teachers choose some children from their class to be buddies for a pupil with an ASD during free time. It's important to involve the pupil with an ASD when making your choice, otherwise they may resist being with the buddies (Perepa, 2014). SNAs are appointed to schools to assist with the care needs of pupils with disabilities. This can include helping with activities like clothing, feeding, and mobility. It is not the role of the SNA to teach pupils or provide educational support, as SNAs are not qualified teachers. All pupils, particularly those with special educational needs, must be taught directly by a class teacher (NCSE, 2016).

\section{Methodology}

This is a case study research where it's using a real life example to this research. This study has recounted a problem which is majority of teachers in international school are not ready to accommodate autistic children in their classroom. This study has only focused on interviews and observations. This qualitative research method required a small sized sample which are human participant to consider a more inside and out of the investigation. There were two females and a male respondent. They were all in the age group of 25 years old to 27 years old. All these respondents are from the same school and have equal amount of experience dealing with autism children in the classroom. The researcher interviewed the participants to make sure all necessary information is collected, some methods for information generation that took into account adaptable and dynamic research, and that included inquiries that were non-order, unstructured, non-institutionalized and open-ended. Besides that, the teachers were observed in classrooms and in their continuing personal development (CPDs). Field notes were taken throughout the observation. This observation is used to study the participant's attitude and skills in accommodating autistic students in their respective classroom.

\section{Results}

The results of this study show an overall positive and negative experiences of teachers in accommodating autistic children in classrooms. As the study only consisted of three respondents, the researcher had both positive and negative results. Based on the findings, based on qualifications all three respondents have the basic teaching certification and licences. All three respondents have not got certification on special need education. Not all experienced teachers have had the opportunity to acquire the necessary knowledge and skills. This includes being able to identify children individual learning needs; planning and implementing evidence informed learning programmers to meet these needs; and recording and monitoring progress and outcomes all three respondents has no qualification in handling autistic children, but respondent 2's past experience has helped respondent 2 to accommodate autistic children in respondent 2's classrooms. In terms of knowledge and 
INTERNATIONAL JOURNAL OF ACADEMIC RESEARCH IN BUSINESS AND SOCIAL SCIENCES

Vol. 10, No. 7, July, 2020, E-ISSN: 2222-6990 @ 2020 HRMARS

experience participant one is still undergoing ongoing trainings which is provided by the school. Whereas, participant two the school has not given any training in the school. Teachers at school will have to figure out the way on how to handle and accommodate these autistic children in the classroom. The respondents did encounter challenges in the beginning of the career. Later on for respondent 1 , the training helped a lot and for respondent 2 , was still struggling in accommodating ASD students in the classroom and same goes to respondent 3 who had no idea on how to handle the autistic child in the classroom. All these respondents at the end has no proper interaction with the autistic child as the learning assistants are the ones who spends most of the time with the autistic child.

All the respondent always gave more attention to the lesson than the autistic children in their classroom. Respondent 2 and respondent 3 has mentioned that it is difficult for them to handle these autistic children in their classroom. Respondent 2 also mention that respondent 2 has no patience in handling the autistic children in respondent 2's classroom. Respondent 1 will have a different approach in teaching the autistic children in the classroom. The autistic children were given a differentiated task by respondent 1 . Whereas respondent 2 gives the same task to the autistic children in the classroom and that to be helped by the PLAs and shadows of the autistic children. Respondent 3 also gave the same task and the same aims that needs to be achieved like the rest of the students to the autistic children in respondent 3's classroom. Respondent 3 just abandon the autistic child and left them to do their own work in the classroom and respondent 3 didn't take the initiative to try to help the autistic child to do the work give or at least to see what they have understood so far. None of the attempt was made by respondent 3 and the learning assistant. Overall, only respondent 1 has a little knowledge on how to accommodate and ready to teach these autistic students. The rest of the respondents has no knowledge nor experience to accommodate the autistic students in the classroom. They have faced many challenges and difficulties in the classroom and these 2 other respondents were ignorant towards the autistic children in the classroom.

\section{Discussion}

Teachers should have a minimum of three years' teaching experience (post probation) before taking up a position in a special setting for autistic children to allow time for development and upskilling. Teachers must be comfortable with hypothesis and research concerning best rehearses for autistic children range issue, including strategies for applied conduct examination, naturalistic learning, spontaneous educating, confident innovation, socialization, correspondence, consideration, adjustment of the environment, language intercessions, appraisal, and the viable utilization of information accumulation frameworks. Explicit issues in speculation and support of practices additionally influence the requirement for preparing in strategies for training autistic children range issues. The wide scope of IQ scores and autistic children, from significant mental impediment and serious language debilitation to prevalent insight, make the requirement for preparing of staff considerably more prominent. To empower teachers to satisfactorily work with guardians and with different experts to set proper objectives, teachers need recognition with the course of autism and the scope of potential results.

Finding affirmed teachers in a custom curriculum has consistently been a daunting task. On the off chance that there is a lack when all is said in done specialized curriculum, that deficiency is considerably increasingly genuine in the developing field of autism. Without a precise information framework in and crosswise over states, nobody realizes what number of experts 
are being prepared, what number of preparing projects are operational, or the expert trains that are included. Of concern isn't just the arrangement of a custom curriculum teacher or early interventionists. Flexible, ongoing training and support are required in order for educators to adequately and appropriately serve students with ASDs in a variety of settings (Sandford \& Cheryl, 2009). It is necessary in all schools to provide necessary training for the teachers who teach autistic children in the classroom. The training provided will definitely ensure the teachers to be more adequate in accommodate these autistic children in the classroom. Teachers confront difficulties in their first years of the profession and they cannot teach effectively. Special education teacher training programs must be improved by carefully evaluating the needs of the pre- and in-service teachers. Undergraduate programs of special education teacher training must contain more practice (Ergül, Baydik \& Demir, 2013).

\section{Conclusion}

Teacher's readiness, knowledge and preparation to accommodate autistic children in a classroom is very important as they are very special and different to the other children. Before an autistic child is put into an international school, the school must only accept the child if they are well equipped with facilities and well trained teachers to educated these special children. International schools should not take in these autistic children if they are not prepared to face and educate them in an appropriate way. All international schools who accepts autistic children into the school have to provide necessary training for the teaching staff on how to handle and accommodate these autistic children in the classroom. Not only training, the school has to have necessary facilities in the classroom and around the school for these special children who are autistic.

\section{Acknowledgement}

The authors would like to define their greatest appreciation to the teachers who took part in the study and the schools which allowed to collect data in order to complete this study.

\section{Corresponding Author}

Noshini Uithayakumar,

Faculty of Human Development, Universiti Pendidikan Sultan Idris,

Malaysia

Email: noshini.uithayakumar@gmail.com

\section{Reference}

Damore, S. J., \& Murray, C. (2009). Urban elementary school teachers' perspectives regarding collaborative teaching practices. Remedial and Special Education, 30(4), 234-244

De Nysschen, S. (2008). Exploring the emotional well-being of educators teaching learners with Autism. Unpublished master's dissertation. Faculty of Education, University of KwaZulu Natal. SouthAfrica.

Dieringer, S. T., Porretta, D. L., \& Sainato, D. (2017). Music and On-task Behaviors in Preschool Children with Autism Spectrum Disorder. Adapted Physical Activity Quarterly, 34(3), 217-234.

Ergul, C., Baydik, B., \& Demir, S. (2013). Opinions of In-Service and Pre-Service Special Education Teachers on the Competencies of the Undergraduate Special Education Programs. Educational Sciences: Theory and Practice, 13(1), 518-522 
INTERNATIONAL JOURNAL OF ACADEMIC RESEARCH IN BUSINESS AND SOCIAL SCIENCES

Vol. 10, No. 7, July, 2020, E-ISSN: 2222-6990 @ 2020 HRMARS

Hart, J. E., \& Whalon, K. J. (2011). Creating social opportunities for students with autism Spectrum disorder in inclusive settings. Intervention in School and Clinic, 46(5), 273-279

Lai, M. C. (2015). Subgrouping the autism "spectrum": Reflection on DSM-5, PLOSBiology.

Ozerk, K., Oksendal, E., \& Ozerk, M. (2018). Educational Psychological Counselling and Collective Competence Improvement Related to Autism/Autism Spectrum Disorders (ASD). International Electronic Journal of Elementary Education, 10(3), 339-354

Ozonoff, S., Pennington, B. F., Rogers, S. J. (1991). Executive Function Deficits in High-Functioning Autistic Individuals: Relationship to Theory of Mind. J Child Psychol Psychiatry. 32(7), 1081-1105

Ruppar, A. L., Roberts, C. A., \& Olson, A. J. (2017). Perceptions About Expert Teaching for Students with Severe Disabilities Among Teachers Identified as Experts. Research \& Practice for Persons with Severe Disabilities, 42(2), 121-135.

Sandford, C. A. (2009). Available Classroom Supports for Students with Autism Spectrum Disorders in Public Schools. Intervention in School and Clinic, 46(5), 273-279. 